\title{
Projeto de Aplicação Móvel Utilizando Lean UX: Estudo de Caso no Aplicativo Pratique
}

\author{
${ }^{1}$ Mariana de A. Falcão, ${ }^{1}$ Ramon W. S. Fonseca, ${ }^{1}$ Welliana B. Ramalho, ${ }^{1}$ Sairo \\ Raoni dos Santos, ${ }^{1}$ Joêmia Leilane Gomes de Medeiros
}

\author{
1Universidade Federal Rural do Semi-árido (UFERSA) \\ R. Gamaliel Martins Bezerra, 59515-000 - Angicos - RN - Brazil \\ marianadealbfalcao@gmail.com, raamon.williams@ hotmail.com, \{welliana.ramalho, \\ sairo.santos, leilane.gomes\}@ufersa.edu.br
}

Abstract. The constant presence of smartphones in everyday life has increased the investment in solutions through mobile applications. With so many applications available to the user, it becomes critical to invest in development methodologies that put the user ahead of the process in order to provide a pleasant experience. Among the several methodologies available, Lean UX has been notable for its agile feature, which prioritizes the experience to be designed for the user and reduces the need to produce an extensive amount of deliverables. In view of this, this methodology was applied to the project of the Pratique application, which aims to approach people with common sports interests. The purpose of this work was to adapt and apply Lean UX to the design development of this application.

Resumo. A presença constante de smartphones no cotidiano tem aumentado o investimento em soluções através de aplicações móveis. Com tantos aplicativos disponíveis ao usuário, passa a ser primordial investir em metodologias de desenvolvimento que coloquem o usuário a frente do processo, a fim de proporcionar uma experiência agradável. Dentre as diversas metodologias existentes, o Lean UX vem se destacando por sua característica ágil, em que se prioriza a experiência a ser projetada para o usuário e que diminui a necessidade de se produzir uma extensa quantia de entregáveis. Diante disto, esta metodologia foi aplicada ao projeto do aplicativo Pratique, que tem como objetivo aproximar pessoas com interesses esportivos em comum. Portanto este trabalho teve como finalidade adaptar e aplicar o Lean UX ao desenvolvimento do design deste aplicativo.

\section{Introdução}

Smartphones e tablets estão presentes no cotidiano das pessoas e se tornaram objetos indispensáveis na vida pessoal e profissional de muitos. Eles transformaram a forma como as pessoas vivem e realizam suas atividades diárias. Em 2007, a Apple revolucionou o mundo dos smartphones com o lançamento do primeiro iPhone. Com a popularização do aparelho, os usuários descobriram que ele não era apenas um iPad com Internet, e sim um verdadeiro computador de mão.

Com o lançamento do sistema operacional Android e o surgimento de smartphones com preços mais acessíveis, o uso desse tipo de dispositivo tornou-se cada 
vez mais comum. Diante dessa realidade, o cenário se tornou promissor para o investimento em aplicações móveis. Milhões estão disponíveis para download nas principais lojas de aplicativos e fora delas. O desafio agora é proporcionar ao usuário uma experiência agradável e única para se destacar nesse oceano de opções.

Como forma de sobressair-se entre milhões de aplicações móveis, o aplicativo Pratique procurará oferecer uma experiência focada no usuário e suas principais necessidades. Tendo como objetivo promover a prática esportiva, conhecer o usuário será fundamental para o sucesso da aplicação. Este trabalho relata o projeto do aplicativo seguindo a metodologia Lean $U X$, que prioriza, a partir da fase de projeto e desenvolvimento, a experiência do usuário final no uso da aplicação.

\section{Design da Experiência do Usuário}

Segundo Buley (2013), o termo User Experience (Experiência do Usuário) foi definido por Donald Norman, uma das maiores referências na área de UX, com o objetivo de abranger todos os aspectos que envolvem a experiência do usuário com um produto, indo além dos conceitos de usabilidade e user interface (interface do usuário). De acordo com Norman e Nielsen (2017), uma experiência de alta qualidade deve englobar uma gama de disciplinas, como mostra o diagrama de Saffer (2006) na Figura 1.

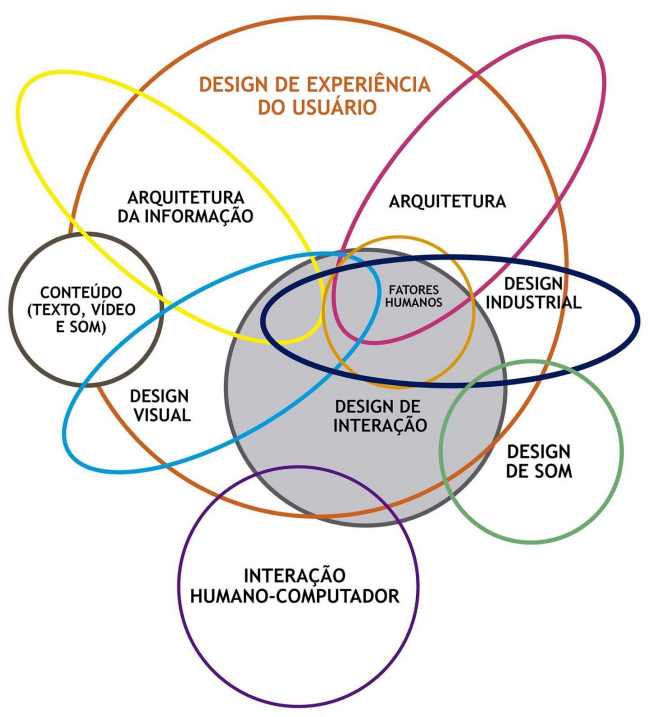

\section{Figura 1. Disciplinas englobadas pelo Design de Experiência do Usuário}

Produtos da Web, como sites e aplicativos, são os que mais necessitam tornar agradável a experiência do usuário, pois são peças complicadas de tecnologia, e quando as pessoas têm dificuldade para entendê-las, geralmente se culpam por isso. É um sentimento irracional de que fez algo errado ou que é incapaz de lidar com artefatos tecnológicos -- uma forma bastante eficaz de fazer com que o usuário desinstale uma aplicação móvel ou abandone um site (GARRETT, 2010). Portanto, preocupar-se em projetar uma boa experiência é fundamental para o sucesso do produto e para a fidelização de seus usuários.

Norman (2014) afirma que, na maioria dos casos, o erro humano é causado pelo design inapropriado de equipamentos ou procedimentos, e faz-se necessário investir no 
design centrado no humano. $\mathrm{O}$ autor reitera a urgência de parar de culpar as pessoas e, em vez disso, projetar para elas.

\section{Lean UX}

O conceito de Lean, que pode ser traduzido como "enxuto", é bastante popular na indústria tradicional. Ele envolve a identificação e eliminação de tudo aquilo que possa causar desperdício (GITAHY, 2017). Guiados pela metodologia Ágil, pelo Design Thinking e pelo Lean Startup, Gothelf e Seiden (2013) desenvolveram a Lean UX (ou UX enxuta), prática que prioriza a entrega mais rápida do produto, com menor ênfase nos entregáveis e maior foco na experiência que está sendo projetada.

Processos de UX costumam ser guiados por requisitos e entregas. No Lean UX, os requisitos são substituídos por premissas. Protótipos são construídos a fim de validar a ideia (GOTHELF; SEIDEN, 2013). O processo iterativo (Figura 2) está dividido em quatro etapas:

- Declarar premissas: a fase de elaboração de premissas consiste em dar oportunidade para que cada membro da equipe possa dizer como solucionaria o problema. Desse modo, um conjunto de possíveis soluções é criado. Essa coleta de opiniões pode ocorrer por meio da dinâmica de grupo brainstorming.

- Criar um MVP: MVP, em português, significa produto mínimo viável. É o conjunto de funcionalidades mínimas de um produto que pode ser colocado em produção como meio de conferir sua viabilidade. Isso evita o desperdício de tempo e esforço em ideias inviáveis. Nessa fase, a equipe determina quais funcionalidades valem a pena testar. O MVP pode ser desenvolvido como protótipo ou não.

- Executar um experimento: nesta etapa, é desenvolvido um protótipo/experiência que simula o uso do produto ou serviço. Deve ser testado com membros da equipe e stakeholders.

- Feedback: os testes são realizados com clientes e possíveis clientes. A partir dos resultados, são obtidos os feedbacks que validarão ou não as hipóteses.

O Lean UX prioriza o porquê de o produto estar sendo produzido. Ele é uma forma de pensamento amplo, abrangendo tudo que envolve o produto (TEIXEIRA, 2015). 


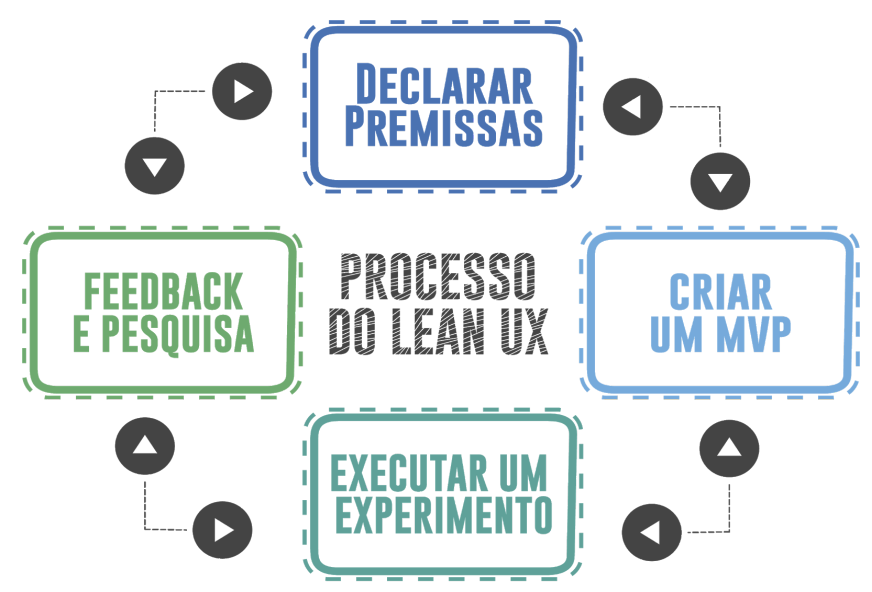

Figura 2. Ciclo do Lean UX

\section{Aplicativo Pratique}

O Pratique foi idealizado por discentes do curso de Bacharelado em Sistemas de Informação durante a disciplina de Interação Humano-Computador da Universidade Federal Rural do Semi-Árido e posteriormente, pré-incubado na incubadora Ineagro Cabugi. O principal motivador desta ideia foi percepção da ausência de prática esportiva no dia-a-dia do brasileiro. Há estudos que mostram que o sedentarismo tem grandes indicadores na população do país, como exibido em Diesporte (2016). A aplicação atuará como uma facilitadora de práticas esportivas, promovendo meios de aproximar os fãs de esportes.

O Pratique apresenta como principais funcionalidades:

- Buscar pessoas geograficamente próximas que possuam as mesmas preferências esportivas que o usuário escolheu no momento do cadastro;

- Marcar partidas e possibilitar que o usuário convide amigos para participar;

- Apresentar, ao usuário, locais (públicos e privados) próximos onde ele poderá praticar suas modalidades preferidas.

A fim de garantir uma boa experiência para os usuários do Pratique, foi utilizada a metodologia Lean UX no desenvolvimento do aplicativo. Os resultados obtidos em cada fase, podem ser observados na seção seguinte.

\section{Resultados}

\subsection{Problema e suposições}

Muitas pessoas gostariam de praticar determinados esportes, mas por não ter companhia ou não conhecer locais adequados para realizar a prática esportiva, acabam deixando de praticar.

\subsection{Hipóteses}

Foram levantadas as seguintes hipóteses a respeito dos usuários e suas necessidades: 
- H1: Acredita-se que as pessoas possuam dificuldade para encontrar companhias para praticar esportes.

- H2: Acredita-se que as pessoas possuam dificuldade para encontrar locais de treino para determinados esportes.

- H3: Acredita-se que as informações que as pessoas querem saber sobre as outras são: confiabilidade, o nome, o sexo, onde moram, quais esportes praticam, dias disponíveis.

- H4: Acredita-se que as informações que as pessoas querem saber sobre os locais de treino são: segurança, localização, para quais esportes são adequados, quais os profissionais que lá trabalham.

- H5: Acredita-se que os usuários gostariam de ter a opção de filtrar suas buscas, tanto pessoas (de acordo com sexo, km's e esportes) quanto locais (público/privado, esportes, km's).

- H6: Acredita-se que as pessoas gostariam de qualificar os locais onde frequentam e as pessoas com quem praticam.

- H7: Acredita-se que os cinco esportes mais praticados por nosso público-alvo são: corrida, futebol, futsal, vôlei e musculação.

- H8: Acredita-se que os cinco esportes que as pessoas mais tem vontade de praticar são: natação, basquete, corrida, vôlei e futebol.

\subsection{Proto-personas}

Diante do levantamento das hipóteses, foram elaboradas as seguintes proto-personas:

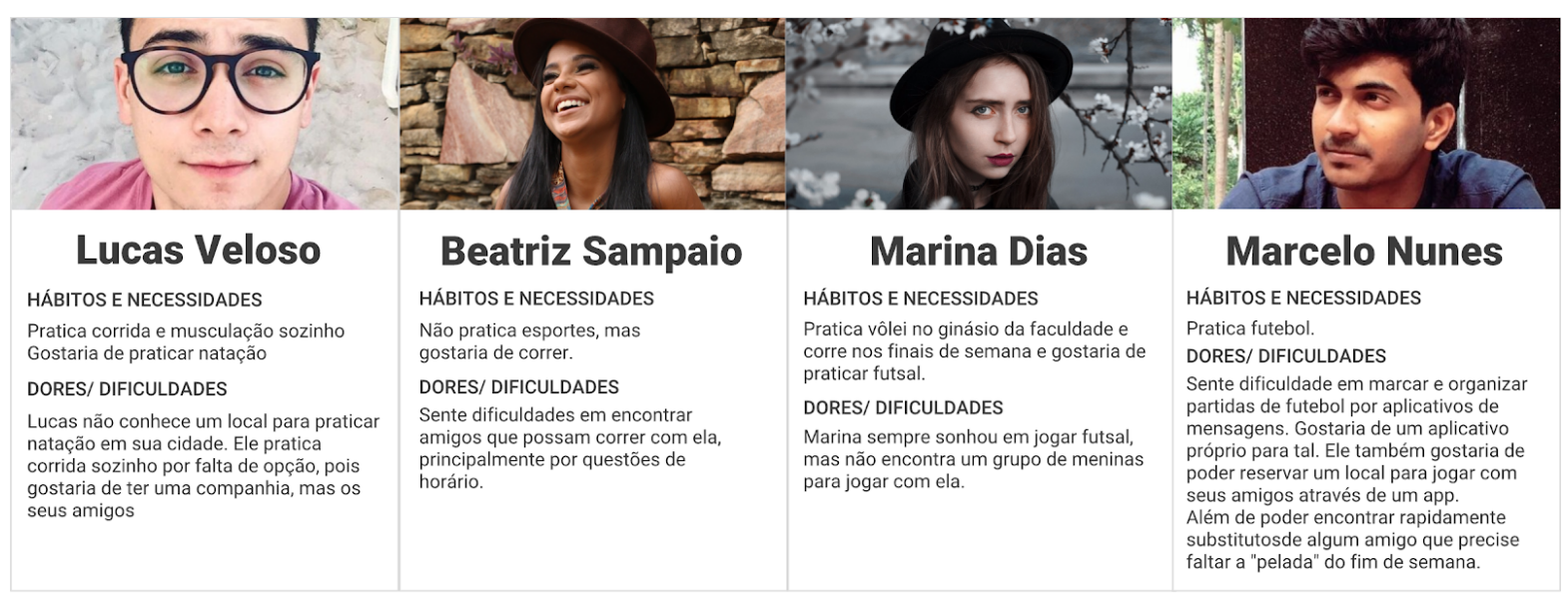

Figura 3. Resumo das proto-personas

\subsection{Funcionalidades}

Gothelf e Seiden (2013) propõe a construção de uma tabela (como a apresentada abaixo) para organizar as funcionalidades a serem testadas, a fim de entender a quem elas atendem e qual seu objetivo. 
Tabela 1. Tabela que relaciona as funcionalidades com as proto-personas

\begin{tabular}{|c|c|c|}
\hline Nós vamos & para & a fim de \\
\hline $\begin{array}{l}\text { Permitir que o } \\
\text { usuário } \\
\text { busque outro } \\
\text { por meio de } \\
\text { geolocalizaçã } \\
\text { o e esportes } \\
\text { preferidos }\end{array}$ & $\begin{array}{l}\text { Todas } \\
\text { personas }\end{array}$ & $\begin{array}{l}\text { Que o usuário encontre rapidamente pessoas } \\
\text { próximas com mesmos interesses esportivos }\end{array}$ \\
\hline $\begin{array}{l}\text { Permitir ao } \\
\text { usuário filtrar } \\
\text { a busca por } \\
\text { novos amigos }\end{array}$ & Marina & $\begin{array}{l}\text { Que o usuário busca apenas as pessoas com as } \\
\text { características que lhe interessa }\end{array}$ \\
\hline $\begin{array}{l}\text { Permitir que o } \\
\text { usuário } \\
\text { busque locais } \\
\text { de prática } \\
\text { esportiva nas } \\
\text { proximidades. }\end{array}$ & $\begin{array}{l}\text { Lucas } \\
\text { Marina }\end{array}$ & $\begin{array}{l}\text { Encontrar mais facilmente locais de prática para os } \\
\text { esportes escolhidos pelos usuários }\end{array}$ \\
\hline $\begin{array}{l}\text { Exibir as } \\
\text { informações } \\
\text { sobre os locais } \\
\text { de prática }\end{array}$ & $\begin{array}{l}\text { Lucas } \\
\text { Marina }\end{array}$ & Mostrar informações mais detalhadas sobre o local \\
\hline $\begin{array}{l}\text { Exibir as } \\
\text { informações } \\
\text { sobre os } \\
\text { outros } \\
\text { usuários } \\
\end{array}$ & $\begin{array}{l}\text { Todas } \\
\text { personas }\end{array}$ & $\begin{array}{l}\text { Mostrar informações mais detalhadas sobre o } \\
\text { usuário }\end{array}$ \\
\hline $\begin{array}{l}\text { Permitir que o } \\
\text { usuário } \\
\text { atribua nota a } \\
\text { um local }\end{array}$ & $\begin{array}{l}\text { Todas } \\
\text { personas }\end{array}$ & $\begin{array}{l}\text { Criar uma forma de qualificar o local, dando aos } \\
\text { usuários um feedback de qualidade sobre aquele } \\
\text { local }\end{array}$ \\
\hline $\begin{array}{l}\text { Permitir que o } \\
\text { usuário deixe } \\
\text { comentários } \\
\text { sobre um local }\end{array}$ & $\begin{array}{l}\text { Todas } \\
\text { personas }\end{array}$ & $\begin{array}{l}\text { Permitir que os usuários informem aos demais sobre } \\
\text { detalhes importantes sobre os locais, como } \\
\text { segurança, estrutura e qualidade dos profissionais }\end{array}$ \\
\hline $\begin{array}{l}\text { Permitir que o } \\
\text { usuário } \\
\text { atribua nota a } \\
\text { outro usuário }\end{array}$ & $\begin{array}{l}\text { Todas } \\
\text { personas }\end{array}$ & $\begin{array}{l}\text { Criar uma forma de qualificar o usuário, dando aos } \\
\text { outros um feedback sobre aquele usuário }\end{array}$ \\
\hline
\end{tabular}




\begin{tabular}{|l|l|l|}
\hline $\begin{array}{l}\text { Reservar } \\
\text { locais } \\
\text { privados }\end{array}$ & Marcelo & $\begin{array}{l}\text { Permitir que, além de encontrar o local, o usuário } \\
\text { consiga reserva-lo para uma determinada data }\end{array}$ \\
\hline Criar eventos & Marcelo & $\begin{array}{l}\text { Permitir que o usuário crie partidas, convidando os } \\
\text { amigos e escolhendo local e hora }\end{array}$ \\
\hline
\end{tabular}

\subsection{MVPs}

\subsubsection{MVPs não protótipos}

A fim de conhecer um pouco mais sobre as dificuldades e preferências dos possíveis usuários do aplicativo Pratique e de validar algumas hipóteses, foi realizada uma pesquisa quantitativa com residentes das cidades de Angicos e Mossoró, ambas situadas no estado do Rio Grande do Norte. Com a aplicação de um questionário online por meio da ferramenta Google Forms, foram coletadas informações sobre pessoas que praticam esportes e também sobre as que não praticam, mas gostariam.

Agregando as respostas dos dois questionários (foi realizado um para cada cidade), totalizam-se 222 respostas. 34,23\% dos entrevistados responderam que praticam esportes; $35,59 \%$ que não praticam, mas gostariam e 30,18\% que não possuem interesse em esportes. Portanto, as hipóteses 1 e 2 foram validadas.

Em relação aos esportes praticados, descobriu-se que $36,84 \%$ praticam corrida, $27,63 \%$ futebol, 26,32\% vôlei, 23,69\% futsal e 22,37\% musculação, validando assim a hipótese 7. Enquanto $51,90 \%$ das pessoas que não praticam querem praticar natação, $27,85 \%$ corrida, $25,37 \%$ futsal, $22,78 \%$ vôlei e $16,46 \%$ futebol, validando parcialmente a hipótese 8 , pois descobriu-se que as pessoas preferem futsal e não basquete. Apoiado nessas informações, o aplicativo Pratique, em sua versão inicial, priorizará estes seis esportes.

Dentre os não praticantes, foi observado que 65,77\% querem praticar algum esporte mas não o fazem por falta de tempo $(56,96 \%)$, de vontade $(39,24 \%)$, por desconhecer locais para praticar seu esporte favorito $(37,97 \%)$, por não ter companhia $(32,91 \%)$ ou por problemas financeiros $(1,27 \%)$.

\subsubsection{MVPs protótipos}

Ao longo do processo de design do Pratique, foram desenvolvidos protótipos. Primeiramente, surgiram alguns esboços de telas. Em seguida, foram desenvolvidos wireframes de papel mais trabalhados e preocupados com a estrutura de apresentação dos elementos na tela. A escolha de trabalhar inicialmente com protótipos de papel de baixa fidelidade se deu pela facilidade de mudanças na estrutura.

Para os testes de usabilidade com os usuários foram desenvolvidos protótipos de alta fidelidade com a ferramenta Adobe Experience Design, mais conhecida como Adobe XD. Gothelf e Seiden (2013) afirmam que, com este tipo de protótipo, é possível colher feedbacks relacionados ao fluxo de navegação, design visual e as expectativas do usuário em relação a interação com os elementos presentes na tela. 
Os testes dos protótipos foram realizados com quatro pessoas, sendo uma do sexo feminino e três do sexo masculino, sendo duas praticantes de esportes e outras duas não praticantes, mas que gostariam de iniciar na prática esportiva. Como Gothelf e Seiden (2013) sugerem, os testes foram precedidos de uma entrevista inicial para garantir que os entrevistados estavam dentro do público-alvo do aplicativo. Após a entrevista, foram entregues tarefas para cada testador. Eles tinham que executá-las em um protótipo clicável de alta fidelidade.

Nem todos os objetos presentes na interface eram manipuláveis e, por esta razão, foi solicitado que os testadores falassem como eles imaginavam que se daria a interação com tais objetos. Pôde-se observar que os usuários sabiam como interagir com todos os elementos não-manipuláveis. Por exemplo, o botão "criar evento", o botão de "enviar mensagem" para outro usuário e o perfil dos profissionais de academias privadas.

Durante os testes, alguns usuários ficaram confusos quando lhes foi solicitado para deslogar da conta. Isto porque, para sair da conta, o usuário precisa acessar o menu e clicar em sair. Dois testadores selecionaram o ícone do chat (que ficava ao lado direito da parte superior da tela) em vez do nome "Menu" (que ficava ao lado esquerdo da parte superior da tela). Eles alegaram que a confusão aconteceu devido ao fato do ícone do chat possuir três traços semelhantes ao do menu hambúrguer.

Por isso, foram retirados os traços dos ícones do chat e posteriormente, ele foi adicionado à barra de navegação da parte de baixo da tela. Como o menu geralmente fica na parte de cima, isto também pode ter aumentado a confusão. Consequentemente, o ícone de notificações passou a ocupar o local que antes estava reservado para o ícone do chat. Estas modificações podem ser vistas na Figura 4.

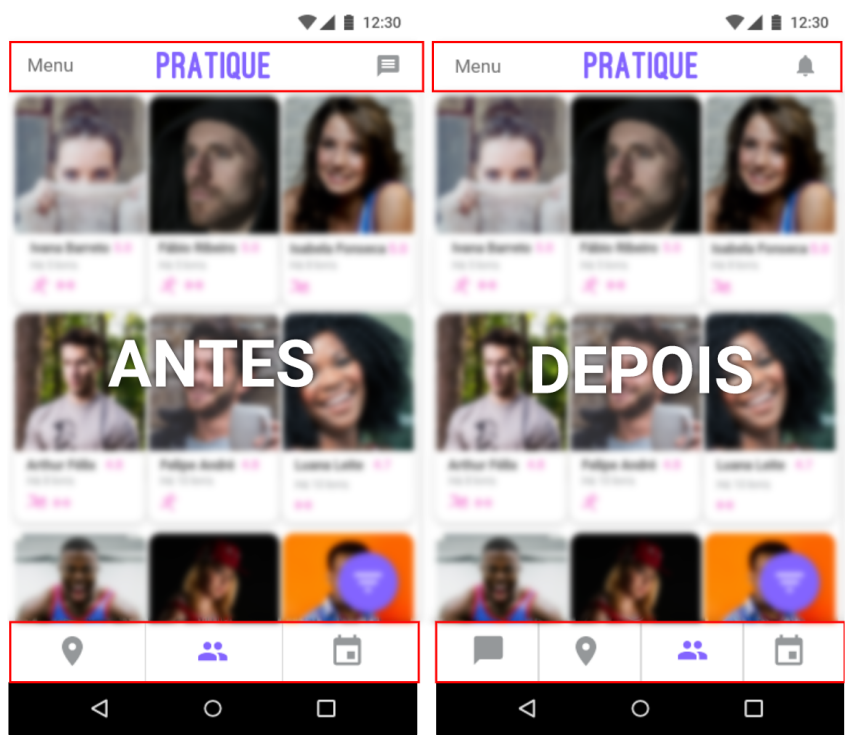

Figura 4. Mudanças nas barras superiores e inferiores

Foi observado também que os testadores não entenderam muito bem a atribuição de notas para os usuários e locais. Notou-se uma dúvida sobre qual seria a nota máxima, se os outros usuários poderiam visualizar quem os qualificou e qual foi a nota dada. Por esta razão foram realizadas as modificações que podem ser observadas na Figura 5. 


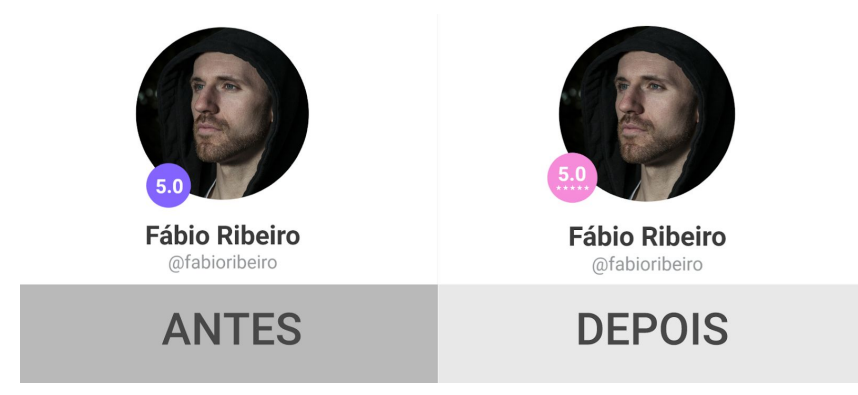

Figura 5. Modificações realizadas no que diz respeito à avaliação do usuário

Como pôde-se observar na Figura 5, foi acrescentado o quantitativo de estrelas abaixo do valor numérico da nota. A quantidade de estrelas diz respeito ao valor máximo da nota, que no caso é 5. A cor do elemento gráfico também foi alterada para mostrar ao usuário que aquele não é um item clicável (durante todo o design, os itens clicáveis tem apresentado a cor roxa) e, portanto, ele não poderá clicar e visualizar quem o qualificou.

Os perfis dos usuários e dos locais trouxe informações conforme especificado nas hipóteses 3 e 4. Quando perguntado aos testadores se aquelas informações eram suficientes, surgiu o insight da inclusão de uma melhoria no perfil de usuários e locais que aumentaria a confiabilidade. Este insight foi incluído no protótipo como pode ser observado na Figura 6. Apesar disto, os testadores afirmaram que as demais informações presentes nestas telas eram importantes, validando assim, as hipóteses 3 e 4.

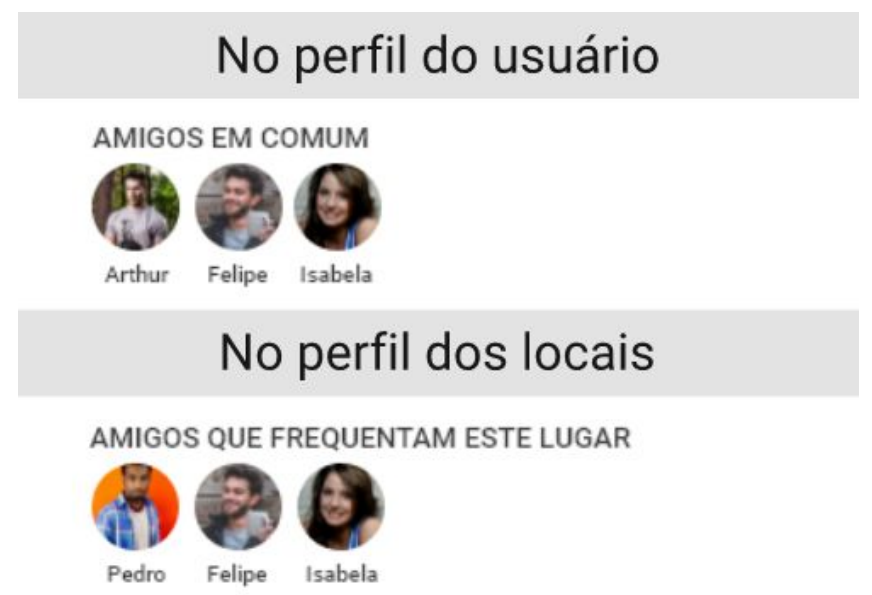

Figura 6. Informações adicionadas aos perfis dos usuários e dos locais

Para confirmar a hipótese 5, foi solicitado que os usuários filtrassem os locais e as pessoas. O objetivo era descobrir se o ícone usado para o botão de filtro não seria um gargalo, mas todos os usuários reconheceram sua função rapidamente. Eles também consideraram que aquela funcionalidade era importante. Afinal, esta opção coloca os usuários no controle do sistema, uma vez que lhes permite alterar as preferências que definiram anteriormente. 
Após o término do teste com protótipo, foram feitas novas perguntas aos testadores. Nesta fase, constatou-se que todos consideraram importante a qualificação de locais e amigos, e que estas informações os deixariam mais seguros em utilizar o aplicativo, o que valida a hipótese 6 .

As perguntas finais também abordaram fatores de usabilidade, como qualidade de uso, facilidade de aprendizado, clareza de textos e ícones e a agradabilidade do design visual. Os feedbacks foram bastante positivos, sendo o grande gargalo o ícone de chat no canto superior direito.

\section{Conclusão}

O presente trabalho teve como objetivo geral aplicar uma metodologia de desenvolvimento de aplicativos móveis considerando experiência do usuário. A Lean UX foi escolhida para ser aplicada ao desenvolvimento do aplicativo Pratique devido sua característica ágil e centrada no usuário, além de ser uma metodologia enxuta, que diminui a necessidade de uma grande produção de entregáveis e acelera o desenvolvimento. Pode-se observar também que a metodologia possibilita um rápido feedback dos usuários, o que permite uma rápida resolução dos problemas encontrados.

Estas características ajudaram na construção de um design agradável, que permite ao usuário realizar suas tarefas sem maiores dificuldades. Sendo assim, este trabalho produziu protótipos de alta fidelidade que devem ser seguidos como base para o desenvolvimento do aplicativo Pratique.

\section{References}

Buley, L. (2013) “The User Experience Team of One: A Research and Design Survival Guide.”, Rosenfeld Media, New York.

Garrett, J.J. (2010) "Elements of user experience, the: user-centered Design for the web and beyond.", Pearson Education.

Gitahy, Y. (2017) "Entenda o que é Lean Startup", https://www.sebrae.com.br/sites/PortalSebrae/artigos/entenda-o-que-e-lean-startup, 0 3ebb2a178c83410VgnVCM1000003b74010aRCRD, Outubro.

Gothelf, J. and Seiden, J. (2013), "Lean UX: Applying Lean Principles to Improve User Experience”, O’reilly Media, Inc., Sebastopol.

Norman, D. (2014) "Human Error? No, Bad Design", https://getpocket.com/a/read/594125970, Setembro.

Norman, D. and Nielsen, J. (2017) “The Definition of User Experience (UX)”, https://www.nngroup.com/articles/definition-user-experience/, Setembro.

Saffer, D. (2006) "Designing for Interaction: Creating Smart Applications and Clever Devices", New Riders, Berkeley. 